primary KI (PWIDs, bunk owners etc.) validated information collected during L1.

Results The study identified 3837 PWID spots in 10 states. The total size estimate for all PWIDs is 49,876 while the size of female PWIDs is 11,031 across10 states. Oyo state had the highest number of PWIDs (all) with an estimate of 14,741, followed by Kaduna 9,232, Kano 6,859 and Gombe 6,577. However for female PWIDs, Kaduna state had the highest 3,340, followed by Oyo 2,711, Abia 1,180 and Gombe 1,028. Conclusion Through this study, Nigeria can plan and implement integrated HIV/Reproductive health services, where female PWIDs are located.

Disclosure No significant relationships.

\section{P803 ASSESSING CORRECT KNOWLEDGE AND POSITIVE ATTITUDE TOWARDS HIVIAIDS TRANSMISSION HOMELESS WOMEN IN INDIA}

Mithlesh Chourase*. International Institute for Population Sciences, Department of Public Health and Mortality Studies, Mumbai, India

10.1136/sextrans-2019-sti.855

Background Despite a significant reduction in the prevalence of HIV in India in the recent past, India's HIV epidemic contributes significantly to the global epidemic. The homeless women are highly vulnerable to risky sexual behavior and its negative health consequences due to adverse conditions of street life. This study attempted to understand the familiarity of term HIV/AIDS, correct knowledge about the modes of transmissions, and ways of prevention.

Methods The study used the data that was collected from 300 homeless women both from those living in night shelter and those are living outside in Delhi in 2015. A structured questionnaire was used to collect various information related to knowledge and attitude towards HIV/AIDS. Correct knowledge was assessed using 8 items, while the attitude towards HIV/ AIDS assessed using 6 preventing measure related questions. The score of knowledge index varies from 0 to 8 and categorized as not heard about HIV/AIDS (0), low (1-4), average (5-6) and high (7-8). Similarly, the score of attitude index varies from 0 to 6 and categorized as not heard about HIV/ AIDS (0), negative attitude (1-3) and positive attitude (4-6).

Results Majority of the homeless women (64\%) are not familiar with the term HIV/AIDS. Of 300 homeless women, 5.3\% had high knowledge, while $18 \%$ had average and $12.7 \%$ had low. Majority of the respondents were not able to report the correct answers on specific questions on HIV/AIDS transmission. Similarly, only $7 \%$ had a positive attitude and $29 \%$ had a negative attitude towards HIV/AIDS.

Conclusion Though there are already many organizations, Government and donors are working with the homeless women for better development and quality life in Delhi, it is equally important to address the critical issues like knowledge about risky sexual behaviour and the attitude towards prevention of HIV/AIDS as many of the homeless women often indulge in risky sexual behaviour.

Disclosure No significant relationships.

\section{P804 BEHAVIORAL RISK FACTORS FOR SEXUALLY TRANSMITTED INFECTIONS AND HEALTH-SEEKING BEHAVIOR OF HOMELESS WOMEN IN DELHI, INDIA}

${ }^{1}$ Mithlesh Chourase*, ${ }^{2}$ Bidyadhar Dehury. 'International Institute for Population Sciences, Department of Public Health and Mortality Studies, Mumbai, India; ${ }^{2}$ India Health Action Trust, Lucknow, India

\subsection{6/sextrans-2019-sti.856}

Background The homeless women living in street areas especially in metro cities like Delhi are the most vulnerable population groups as they don't have privacy and also don't have self-dignity to express their healthy sexual and reproductive health. There are no explorative studies available in the literature on sexual and reproductive health among homeless women. In this context, this research is attempting to understand the behavioral risks for STIs and health-seeking behaviour among the homeless women in Delhi.

Methods Primary data was collected to explore the sexual and reproductive health among the homeless women above 15 years living in Delhi in 2015. A total of 300homeless women were interviewed on sexual and reproductive health. As this study is explorative, both quantitative and qualitative methods of data collection was used.

Results About one-third, homeless women had intercourse before the age of 13 years and $85 \%$ had before age of 18 years. Two-third women reported the first intercourse happened forcefully and only $12 \%$ of women used a condom at that time. About $10 \%$ of women had sex with multiple partners in the last six months. Use of a condom during sex is not common women as only $40 \%$ ever had used a condom. As reported by the respondents, sex without concern, lack of information and lack of accessibility for a contraceptive method emerge as the major reasons for not using a condom during sex. About $40 \%$ were suffered from STI at the time of the survey.

Conclusion This research explored the sexual behavior and condom use to avoid unwanted pregnancy as well as to avoid STI. The treatment-seeking behaviour for RTI/STI was found to be very low. The study suggests that it is necessary to make awareness of the benefits of protected sex and also condoms should be distributed frequently homeless women to have protected and healthy sexual life.

Disclosure No significant relationships.

\section{P808 CORRELATES OF SEXUALLY TRANSMITTED INFECTIONS SYMPTOMS AMONG MALE PRISONERS IN IRAN, 2013: A NATION-WIDE SURVEY}

${ }^{1}$ Armita Shahesmaeili, ${ }^{2}$ Mohammad Karamouzian*, ${ }^{1}$ Mostafa Shokoohi, ${ }^{1}$ Fatemeh Tavakoli, ${ }^{1}$ Hamid Sharifi, ${ }^{3}$ Mohammad Hassan Rabiee. ${ }^{1}$ HIV/STI Surveillance Research Center, and WHO Collaborating Center for HIV Surveillance, Institute for Futures Studies in Health, Kerman University of Medical Sciences, Kerman, Iran; ${ }^{2}$ School of Population and Public Health, Faculty of Medicine, University of British Columbia, Vancouver, Canada; ${ }^{3}$ Department of Epidemiology, Faculty of Veterinary Medicine, University of Tehran, Tehran, Iran

\subsection{6/sextrans-2019-sti.857}

Background HIV prevalence among prisoners is over eight times higher than that of the general in Iran. Considering that sexually transmitted infections (STIs) increase the susceptibility to HIV infection, this study estimates the prevalence and correlates of STI-related symptoms among prisoners in Iran. 
Methods In this cross-sectional study, 27 prisons across 16 provinces were selected using a stratified random sampling approach. Men aged $\geq 18$ years who spent at least 1 week in the prison and self-reported having had sex during last year were eligible for this analysis. Participants were asked about their current STI symptoms including penile discharge (PD) and genital ulcers (GU). Demographic variables, HIV/STIrelated knowledge, STI care seeking practices, HIV self-perceived risk, as well as history of substance use, incarceration, and sexual behaviours were collected using a face-to-face pilot-tested risk assessment questionnaire. HIV tests were completed using ELISA of dried blood spots. Correlates of having STI symptoms were identified using descriptive statistics and logistic regression models.

Results Out of 2610 male prisoner recruited (Mean age \pm SD: $35.7 \pm 0.19$ ), $7 \%$ reported symptoms for PD, UC, or both; $45 \%$ of whom had not sought STI care inside prisons. Having STI-related symptoms were positively associated with a history of injection drug use (adjusted odds ratio [AOR]: 2.1, 95\% CI, 1.4-3.1), condom accessibility inside prison (AOR: 1.7, 95\% CI , 1.1-2.8), self-perceived risk of HIV (AOR: 1.5, 95\% CI , 1.1-2.2), HIV-seropositivity (AOR: 3.3, 95\% CI , 1.3-10.6), while negatively associated with having sufficient STI-related knowledge (AOR: 0.6, 95\% CI, 0.4-0.8).

Conclusion STI symptoms are notable among prisoners in Iran with a higher prevalence among specific groups (i.e., those who inject drugs and live with HIV). Our findings call for revisiting current HIV/STI prevention policies across Iranian prisons to help improve prisoners' HIV/STI knowledge and encourage their HIV/STI preventive practices.

Disclosure No significant relationships.

\section{P809 NEGOTIATING SAFER SEXUAL RELATIONS WITH HUSBAND AND ASSOCIATED STI/HIV VULNERABILITIES AMONG MARRIED WOMEN IN INDIA}

Deepanjali Vishwakarma*, Santosh Sharma. International Institute for Population Sciences, Population Studies, Mumbai, India

\subsection{6/sextrans-2019-sti.858}

Background In India, sexually transmitted infections (STIs) and HIV, take an enormous toll on women's sexual/reproductive health, yet preventive programmes are lacking as married women's risks are frequently underestimated. Husbands continue to be the greatest source of STIs including HIV to their wives. Being able to negotiate safe sex is critical to the prevention of HIV/AIDS and other STIs. Therefore, the present study has mainly focused to analyze the women's attitudes toward safer-sex negotiation if husband has a STI and associated risk of STI/HIV among married women in India.

Methods National Family Health Survey (NFHS-4, 2015-16) collected information from a nationally representative sample of 121,118 women age 15-49 years has been analyzed by using descriptive and multivariate techniques. Women were asked that a wife is justified in refusing to have sexual intercourse with her husband if he has a STI.

Results Overall $78 \%$ of women agree that a wife is justified in refusing to have sex with her husband if he has a STI. A higher proportion of women who were agreed that a wife is justified to negotiate sex were from 25-29 years of age, residing in urban area, those who were higher educated and belongs to highest wealth quintile. Results revealed that the likelihood of a woman holding this belief increased with her autonomy, as measured by participation in household decision making and rejection of wife beating $(p<0.001)$. Women who were away from home for one or more month were significantly less likely to agree. Other significant predictors were knowledge/awareness of STIs (OR-1.13 p $<0.01)$. Those women who agreed towards negotiating sex were significantly less likely to have a STI.

Conclusion Our findings suggest that sexual health education programmes may be more effective if they include strategies to address social norms and cultural practices that limit women's autonomy in society.

Disclosure No significant relationships.

\section{P810 HIVISTI SERVICE COVERAGE AMONG KEY POPULATION IN NIGERIA - LESSONS FROM SIZE ESTIMATION STUDY IN ABIA AND TARABA STATES}

${ }^{1}$ Greg Ashefor*, ${ }^{1}$ Adaoha Anosike, ${ }^{1}$ Idoteyin Ezirim, ${ }^{1}$ Olutosin Adebanjo, ${ }^{2}$ Chukumebuka Ejeckam, ${ }^{3}$ Kalada Green. ${ }^{1}$ National Agency for the Control of AIDS, Research Monitoring and Evaluation, Abuja, Nigeria; '2University of Manitoba, Abuja, Nigeria; ${ }^{3}$ Centre for Global Public Health - Nigeria, Abuja, Nigeria

\subsection{6/sextrans-2019-sti.859}

Background Mode of transmission study revealed that 38\% of HIV new-infections in Nigeria are attributable to KPs. Abia and Taraba are two states in Nigeria with an HIV prevalence of $3.9 \%$ and $5.1 \%$ respectively. To ensure KPs receive interventions, estimation study was conducted in both states to provide insight on KP size, distribution and HIV/STI service coverage.

Methods Three KP groups (FSW, PWID, MSM) were mapped in Abia and Taraba. Programmatic mapping was employed which involved two sequential data collection steps known as level one [L1] and level two [L2]. During L1, data was collected from key informants (KIs) on the geographic locations/ spots where KPs congregate, the characteristics of the spots, estimate of KPs found there and HIV/STI service availability. During L2, KI interviews were conducted at spots identified in L1. In L2 interviews primary KIs (FSWs, IDUs, MSM,) validated information collected during L1.

Results 1,136 spots (679 FSW spots, 103 MSM spots, 354 PWID spots) were identified in Abia while Taraba had 574 spots (346 FSW spots, 98 MSM spots, 130 PWID spots). The total KP estimate in Abia is 13,527 while Taraba has 6,246. In Abia, condom and HIV testing were only available in $4.4 \%$ and $1.6 \%$ FSW spots respectively. Also condom and HIV testing were only available in $2.8 \%$ and $1.1 \%$ PWIDs spots respectively. Both services weren't available at MSM spots while all KPs spots had no STI services. In Taraba, condom and HIV testing were only available in $0.6 \%$ and $1.3 \%$ FSW spots respectively. Also condom and HIV testing were only available in $4.2 \%$ and $3.4 \%$ PWIDs spots respectively. Both services weren't available at MSM spots. 0.3\% FSW spots had STI service but other KP spots had no STI services.

Conclusion From this study, Nigeria needs to scale up targeted HIV/STI services for KPs in Abia and Taraba states.

Disclosure No significant relationships. 